Provided for non-commercial research and education use. Not for reproduction, distribution or commercial use.

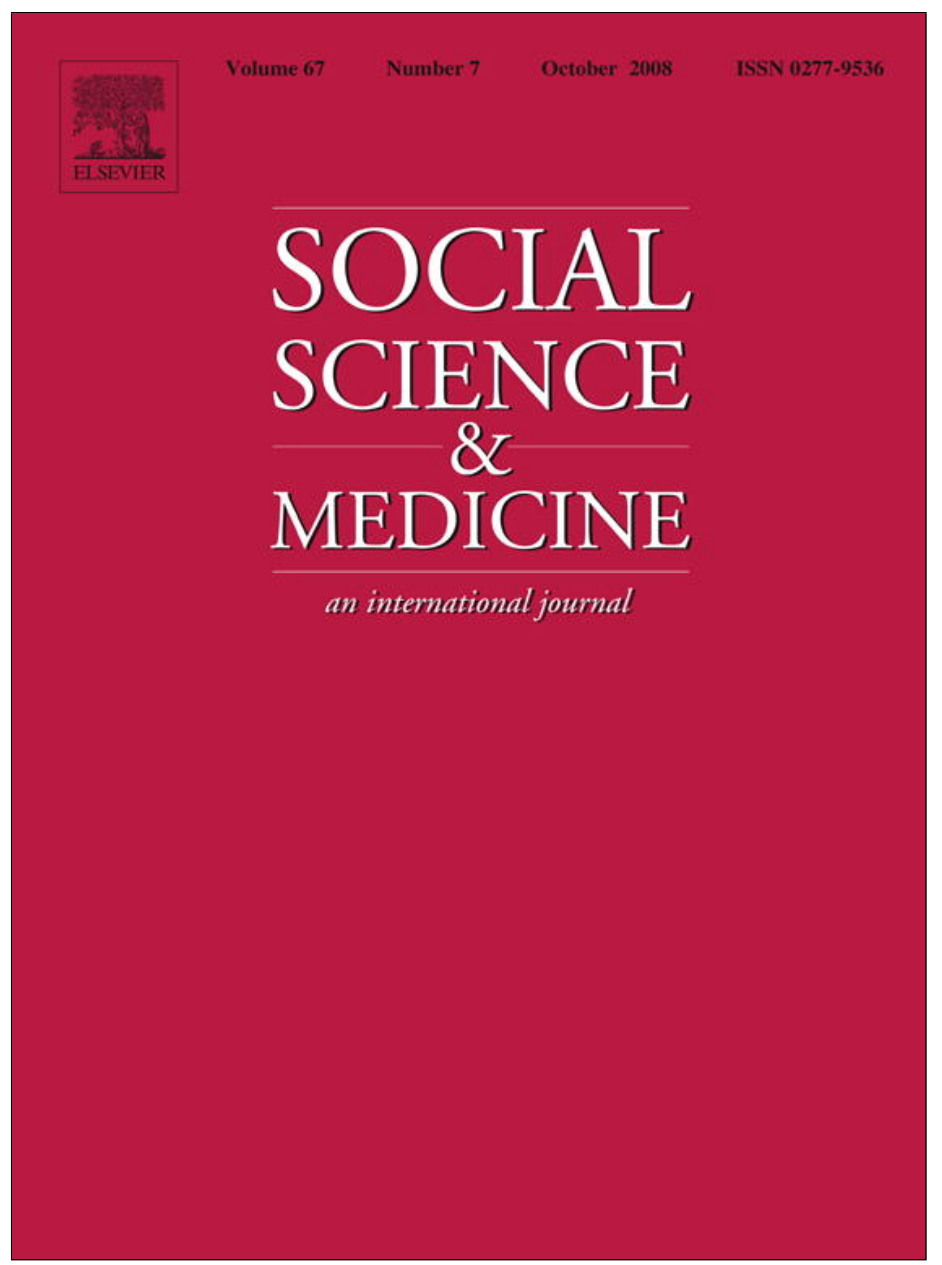

This article appeared in a journal published by Elsevier. The attached copy is furnished to the author for internal non-commercial research and education use, including for instruction at the authors institution and sharing with colleagues.

Other uses, including reproduction and distribution, or selling or licensing copies, or posting to personal, institutional or third party websites are prohibited.

In most cases authors are permitted to post their version of the article (e.g. in Word or Tex form) to their personal website or institutional repository. Authors requiring further information regarding Elsevier's archiving and manuscript policies are encouraged to visit:

http://www.elsevier.com/copyright 


\title{
Are drug treatment services only for 'thieving junkie scumbags'? Drug users and the management of stigmatised identities ${ }^{\text {is }}$
}

\author{
Polly Radcliffe*, Alex Stevens \\ University of Kent, Canterbury, Kent, UK
}

A R T I C L E I N F O

\section{Article history:}

Available online 18 July 2008

\section{Keywords:}

UK

Substance misuse

Drug treatment services

Stigma

Identity

\begin{abstract}
A B S T R A C T
This article uses qualitative interviews with 53 problematic drug users who had dropped out of treatment in England, UK to explore how they describe the stigmatisation of drug users and drug services. It discusses the construction of the category of the junkie through its association with un-controlled heroin use and criminality. It shows how some drug users carefully manage information about their discreditable identities by excluding themselves from this category, while acknowledging its validity for other drug users. The junkie identity was generally seen as shameful and therefore to be avoided, although it holds attractions for some drug users. For many of the interviewees, entry to treatment risked exposing their own activities as shaming, as they saw treatment as being a place that was populated by junkies and where it becomes more difficult to manage discreditable information. The treatment regime, e.g. the routine of supervised consumption of methadone, was itself seen by some as stigmatising and was also seen as hindering progress to the desired 'normal' life of conventional employment. Participation in the community of users of both drugs and drug services was perceived as potentially damaging to the prospects of recovery. This emphasises the importance of social capital, including links to people and opportunities outside the drug market. It also highlights the danger that using the criminal justice system to concentrate prolific offenders in treatment may have the perverse effects of excluding other people who have drug problems and of prolonging the performance of the junkie identity within treatment services. It is concluded that treatment agencies should address these issues, including through the provision of more drug services in mainstream settings, in order to ensure that drug services are not seen to be suitable only for one particularly stigmatised category of drug user.
\end{abstract}

(c) 2008 Published by Elsevier Ltd.
Hey hey we're the junkies

Two hundred junkie criminals are being paid $£ 800,000$ in compensation by the government including a former DRUG DEALER. They get nearly $£ 4,000$ each after

\footnotetext{
is We would like to thank Melony Sanders and Neil Hunt for their work on this project. We thank also the participating drug services and interviewees for their contribution to this research, as well as Beryl Poole for her specialist advice. Jack Levinson, Tim McSweeney and Barry Spunt made helpful comments on earlier drafts of this article for which we are very grateful.

* Corresponding author.

E-mail addresses: p.c.radcliffe@kent.ac.uk (P. Radcliffe), a.w.stevens@ kent.ac.uk (A. Stevens).
}

moaning they were forced to do 'cold turkey' withdrawal from drugs in prison... (The Sun Newspaper, November 14, 2006).

This newspaper story described an out-of-court settlement paid by the Home Office to former prisoners who had been denied treatment for opiate addiction in custody. The use of the term 'junkie' illustrates the close association between drug use and crime in popular discourse. In this paper we examine how the stigmatised identity of the junkie features in the accounts of problematic drug users who have disengaged from treatment and how it affects their perceptions of treatment. 
The term 'junkie' is thought to have originated in the 1920s, derived from New York City ‘junkmen' - heroin addicts who supported their habits by selling scrap metal collected from industrial dumps (Carnwath \& Smith, 2002; Courtwright, 2001). Courtwright distinguishes the emerging category of the junkman from the 'iatrogenic addicts' who had become addicted to morphine through a combination of its widespread prescription for stress and chronic illness, and the invention of the hypodermic needle in the 19 th century. Addiction to morphine via medical practice in America in the early part of the 20th century, and as we shall see, today, conferred a respectability that was not sustained when addiction resulted from using illicit drugs non-medically. The 'junkman' was therefore a morally degenerate drug user on the semi-legal margins of society. Then as now, it is the criminalisation of drug use that sustains this spoiled identity. By the time William Burroughs' autobiographical account of drug addiction in 1940s New York was published (under the pseudonym, Lee, 1953), junk had come to refer to the drugs themselves, rather than to scrap metal, and junkie to the drug takers. The term was apparently imported to London from America in the 1950s, along with the literature, jazz and drug-taking of the Beat life style. The earliest English reference to "junkie" in the Oxford English Dictionary is cited to the 1959 novel, Absolute Beginners by Colin McInnes; a work full of American slang. Junkie is used to refer to a character who is described as having "sad valleys down his cheeks" and is given the same first name as the prototypical hero of the Beat generation, Dean Moriarty. The British development of the junkie identity speeded up in the mid-1960s, and then again in the 1980s through the spread of heroin to new areas and users (Pearson, 1987). It mirrored earlier U.S. developments, with the emergence of younger, working-class male users alongside older, respectable, middle-class users who had become addicted via medical treatment or who had developed an addiction following professional access to drugs (Jamieson, Glanz, \& MacGregor, 1984).

Douglas (Douglas, 1966; Douglas \& Wildavsky, 1982) has discussed how the risks and dangers that are prioritised in any culture are linked to systems of classifying real and symbolic pollution, delineating what Hacking has termed 'literal and figurative filth' (Hacking, 2003). The term 'junkie' originates from the association of a certain category of drug user with rubbish and criminality. As we will show in this article the term continues to reference a residual group that is associated with both dirt and danger.

Notwithstanding some recent research on the social identity of marginalised and disadvantaged drug users (Malins, Fitzgerald, \& Threadgold, 2006; Rhodes et al., 2007), research on the management of stigma associated with drug use has primarily focused on controlled and recreational, middle-class users who tend to avoid statutory drug treatment services and 'recover naturally' from, or 'mature out' of drug use. In contrast to studies of middle-class controlled users, in our cohort only one of the 53 disengaged drug users interviewed had had a professional career and only four had received post-16 education. This paper is concerned with a population for whom the problematisation and management of potentially spoiled identities have rarely been the topic of investigation. It focuses on decisions on whether or not to engage in drug treatment. This can be seen as a 'critical period' (Yang et al., 2007: 1533) in which transitions can be made from normalised to stigmatised identities (or vice versa).

By no means all heroin users enter, or need, treatment. Controlled and regulated use of heroin involve adhering to informal rules on the frequency of use of heroin, with whom it is taken and where it is used (Shewan \& Dalgarno, 2006; Warburton, Turnbull, \& Hough, 2005; Zinberg, 1984). Such opiate users are described as carrying out a tactical risk management that balances the pleasures of heroin use and the dangers of dependency. For such heroin users, it is suggested, descent into junkiedom reflects a life style that can be avoided using strategies of drug use in lives in which heroin sometimes plays a recreational part, but that does not, in the words of Valverde (1998), 'totalise' their identities. As noted by Room (2003), junkie identity is determined by the extent to which other pursuits are subordinate to drug-taking. The notion of addiction is only meaningful in a culture where the self-control of individuals is valued above all, especially the ability to keep time. In Rødner's (2005) study of Swedish drug users' construction of identity, the controlled drug users she interviewed distinguished their own drug use from the junkie's (or Narkomanar's) un-controlled, full-time use. Similarly the typology devised by Boeri (2004) to distinguish the heroin users she interviewed included the dimensions of control over use and the status that users allocated to their social role as heroin users. In Boeri's typology, junkies had no other social role. To capture the character of the junkie's devotion to heroin, Boeri cites Waldorf (1973: 46) who described a process by which the junkie seems to 'roll their lives and the universe into...the single ball of heroin'. The junkie category thus refers to individual lives in which time and space are dominated by drug use (and heroin in particular).

The junkie identity is also closely tied to criminality. While the construction of a causal link between drugs and crime may be advantageous to a wide range of groups including politicians, legalisers, criminal justice and treatment agencies and those offending drug users who wish to absolve themselves of responsibility for their crimes (Carnwath \& Smith, 2002: 134) - it may also have an unanticipated effect on the identities and practices of drug users. Warburton et al. suggest that popular images of heroin use as they are deployed in anti-drug campaigns and government policy ignore the possibility of controlled heroin use and may actually lead to the complex of drug use and offending behaviour associated with the destructive role of the junkie (Warburton et al., 2005: 59). It is the members of this category who have become the most high profile target for government intervention in what Parker (2007) has described as the policy 'hegemony' of heroin, crack and crime. This refers to the shift in British drugs policy since the mid-1990s. Fear of the AIDS epidemic has subsided and increasing emphasis has been placed on the link between drugs and crime (Duke, 2006; Hunt \& Stevens, 2004). This has strengthened the stigmatising association between drug use and offending through what has been 
referred to elsewhere as the 'voodoo criminology'1 of drugrelated crime (Stevens, 2007; borrowing the phrase from Young, 2004). This uses the techniques of the drug test and social survey to exaggerate the scale and causality of the link between drugs and crime. This is done largely by ignoring the limitations of these methods and the dark figures of unknown drug users and offenders which they are unable to detect. Using statistics generated through these methods, the 2003 Cabinet Office strategy report placed great emphasis on the scale of offending by 'high-harm causing users' and recommended that drug policy should focus on gripping these 'HHCUs' and coercing them out of their criminal ways (PMSU, 2003a, 2003b).

This bureaucratic facsimile of the junkie category can also be seen in the more recent Cabinet Office review of crime policy. It identifies heroin and crack as 'high-harm' drugs and endorses the need to 'grip' their users who are 'prolific offenders' and push them into treatment (PMSU, 2007). By concentrating offending drug users in treatment, the identification of the HHCU both elaborates and confirms the notion that treatment services are for junkies.

The possibility that notions about addiction and drug use can become self-fulfilling is an interesting one, and clearly mythologies exist both at the level of commonsense knowledge about drug use and users and in the form of government policy that targets some kinds of drug users. In his ethnography of heroin users, Pearson (1987) quotes respondents who describe the process whereby novice users who are keen to join the ranks of the local drug using network, buy heroin regularly as if they have become dependent upon it - until they have turned themselves into dependent users. For the unemployed users from the deprived parts of northern England studied by Pearson, the drug using network into which they had become habituated represented - at least at first - a source of prestige, social activity and relationships which were often isomorphic with existing family and community networks.

The first part of this paper examines how the drug users we interviewed made use of the junkie category in their discussion of drug users and drug treatment. The second explores how the association of treatment with the junkie identity contributed to an association between treatment entry and shame. In the third part, we argue that the organisation of treatment regimes and the routinised 'work' that is involved for example in adhering to a substitute maintenance prescription programme, may exclude drug users who wish to avoid the junkie identity from treatment and may also have the effect of further fixing drug users' discredited identities, rather than creating opportunities for them to live different lives. In the fourth part of this paper we explore how for some dependent drug users, the flip-side of becoming a junkie is membership of

\footnotetext{
1 By "voodoo criminology", Young means an approach to the study of deviance that ignores three major problems in its measurement. These are the problems of representativeness (whether the sample surveyed is representative of the population of interest), of truth (whether the methods produce a true picture of behaviours, or just socially influenced narratives) and of the plurality of definition (making it hard to measure phenomena for which there is no clearly agreed definition). All three problems apply to the measurement of drug-related crime.
}

a transgressive community that may offer a refuge of sorts from the humiliation of the low wage, 'flexible' economy in and out of which they drift.

\section{Methods}

Interviews were carried out with 53 former clients of 12 randomly sampled drug treatment services in three English Drug Action Team areas, two metropolitan and one provincial. Thirty-nine of the interviewees were men, 14 were women. The age range of the interviewees was between 19 and 50 years old. Forty of the interviewees were White British, four were Black British, five were of Mixed Heritage, two were Irish, one was Asian British and one was a Traveller. These services were providing various forms of outpatient treatment, including opiate substitution prescriptions, day services and structured counselling. Recruitment was carried out via the treatment service records of clients who had dropped out of treatment before three months recommended as optimal by the National Treatment Agency for Substance Misuse and who had given consent for their records to be viewed. We also used snowball sampling from interviewees to identify other potential respondents (Atkinson \& Flint, 2001). We paid interviewees at a level to compensate them for their time and contribution, without constituting an inducement so powerful that it rendered informed choice questionable (Ritter, Fry, \& Swan, 2003; Seddon, 2005). All interviews were based on informed consent. The study was approved by four NHS research ethics committees. It was funded by the Department of Health.

We recognise that, because we were attempting to contact drug users during office hours by letter and by telephone, those who agreed to be interviewed may not be representative of those drug users who are homeless, involved in the night time economy, particularly sex work, those with mental health problems or in custody. While the majority of those interviewed were in receipt of welfare benefits, a significant minority of those interviewed worked, some sporadically, in construction, in sex work, as panel beaters, in sales, as milkmen or in bars. Three of those interviewed were students. Several of those interviewed had spent much time in prison for drug-related offences and several had been attending drug treatment services mandated by court orders as an alternative to custody.

The analysis of the interviews was shaped by our knowledge of the existing literature, themes that had emerged in previous work carried out by the research team and our knowledge of the data. Our analytical approach could therefore be described as adaptive coding (Layder, 1998). There were two stages to the coding process. First, a random selection of interview transcripts was used to identify broad themes in the data. Second, a further 10 interview transcripts were randomly selected and used to check whether or not any other broad themes could be added and to divide the existing broad themes into sub-themes. Once we were satisfied that most of the themes and subthemes had been identified, they were imported into the Nvivo data processing package, along with the interview transcripts and field notes for all qualitative interviews. The use of Nvivo to code documents enabled researchers to create a collaborative coding scheme for the interview 
transcripts. Throughout this article, we have anonymised interviewees - the names used bear no relation to the interviewees' real names.

\section{The stigmatisation of the junkie}

As Goffman (1968) demonstrated, for the discreditable person whose source of shame can be concealed and hidden, there is the possibility of 'passing' as normal; it is information about the source of shame which must be managed. Drug users we interviewed described attempts to manage information about illicit substance use and seeking treatment for it in the face of a 'straight' world in which all drug users are constituted as junkies. As we will show in interview data, the management of identity would seem to involve a balancing act between the individual's own sense of her particular self and her perceived relationships to both a moral community of which she forms a part and communities of 'others' of which she does not.

Zinberg (1984: 153) notes that '[o]ne way in which controlled users can assert their normalcy is to spurn and condemn junkies'. In Rhodes et al.'s study of public injectors in South Wales, the disadvantaged injecting drug users interviewed reported that the 'shunning, dissing and cussing' of junkies come from other drug users (Rhodes et al., 2007: 581). In our interviews, drug users also often repeated and endorsed unsympathetic characterisations of junkies. Interview subjects were seemingly able to accommodate the apparent contradiction of the lived experience of drug use with the existence of junkies as an other, rejected category (Douglas, 1966). This was described vividly by a heroin user whose occasional heroin use had become problematic and who had sought a methadone reduction course via his GP. He was attending a drug treatment service for regular counselling services until he made the discovery that his next door neighbour worked at the treatment service.

Hopefully - she works here - she doesn't think that everyone's a thieving junkie scumbag, do you know what I mean but generally they are. You know and obviously most members of society look down on it, everyone looks down especially on heroin...And that's the way it is, isn't it? And it's true because most junkies are dirty, smelly and really...most of them are because that's what it does to you (Joseph).

In Joseph's view, he is an exception to the rule of the stereotype of the 'thieving junkie scumbag'. Although until recently Joseph had kept his drug use occasional and controlled, and had managed to remain employed throughout, in this extract he, nevertheless, holds with the stereotype of the dirty, smelly junkie 'because that's what [heroin] does to you'. He is able to distinguish his own particular struggle to control his drug use in the context of a busy life from the general category of the junkie whose identity is determined by drug use and whose agency is overwhelmed by heroin.

Despite the notions of inevitable enslavement and criminality that are attached to heroin use, there are alternative identities available for drug users. Reinarman (2005) has described how the lexicon of addiction-as-disease is taught by counsellors, judges, therapists and other drug users, and certainly, the performance of acknowledgment and acceptance (as opposed to denial) of addiction that is required in treatment services provides a possibility for moral redemption from the reprehensible category of junkie. Valverde (1998) has analysed how the one-day-at-a-time motif of Alcoholics Anonymous and its sister organisations provide means for understanding recovery as the habit of staying dry/clean rather than necessarily being linked to the contaminated self of the drinker/addict. The diseased addict, the recovering alcoholic/addict, the normalised 'service users' are all alternative sources of identity for drug users who have embraced treatment programmes and regimes. These are alternative categories of self that are made available to drug users via the treatment process, should they choose to engage in it. The people we interviewed for this study, however, had disengaged from treatment programmes, sometimes because treatment itself was too closely associated with the identity of the junkie and sometimes because of the tempting allure of junkie life.

\section{Shame and the treatment service - 'That is not me'}

The experience of drug treatment itself was stigmatising for many of those interviewed for our study. For some, it was the reason they had disengaged from services. As is consistent with other studies (Copeland, 1997), the association of the junkie identity with treatment services was often central to our respondents ambivalent attitude toward entering treatment. In this section we describe how drug users account for and manage spoiled identities in relation to treatment services.

Many of our respondents were often seeking a life that could be described as conventional and respectable. For some respondents, the first contact with treatment services was reported to be profoundly shocking. It was a moment where their own identity became tainted by association with the junkie identity. Particularly female drug users, drug users whose primary problem was with prescription drugs, cannabis users and younger people did not consider their own substance problems to be of the same type or themselves to be like the 'junkies' and 'smack heads' for whom they perceived the services to be designed.

it's quite frightening sometimes as well, especially when I was on medication prescribed by the doctor, you think, you're an ordinary person and all of a sudden you're put in a world in a waiting room with... heavy drug users as well, who can just take your bag because they want the money (Sharon).

This interview extract illustrates how Sharon is able to distinguish her own identity from that of the "heavy drug users' into whose world she is thrown by entering the treatment service waiting room. A former sex worker in her 50s, her claim to be an 'ordinary person' is derived from her dependency on prescription medication rather than illicit substances. As Courtwright (2001) describes, for this respondent and others interviewed the characterisation of drug use as distinctly medical has moral significance. The disjuncture of the sense of self-described is the revelatory one of seeing oneself from the perspective of a moral community, of which one is also a part. The 
audience she is shamed by is not the 'heavy users' in the treatment service waiting room - or presumably the drug workers she meets there - but herself. As Katz (1999: 149) suggests, one does not need to be seen by others to feel shame: 'What brings shame is taking toward oneself what one presumes is the view that others would have were they to look'.

Although several of the respondents interviewed reported the fear of being seen using drug treatment services as a barrier to continuing treatment, they may also have been ashamed to see themselves using such services. A young woman who had become a problem cannabis user described her fears of the consequences of being seen entering the drug treatment service in the town where she lives:

I don't want anyone to see me and say, oh, look, because then they start making assumptions, is she a smackhead, you know (Elaine).

The shame of becoming visible as a user of a drug treatment service and associated with its client group represents a failure to control information about oneself. Elaine speaks of the fear of being connected by others to a category that she does not recognise herself as belonging to. The fear, whether real or imagined, of being given a stigmatised identity by others is about a sense of self in relation to a moral community.

Such concerns about exposure as a user of drug services and being identified as a junkie - were not exclusive to women and non-opiate drug users, however. An example comes from a long term user of heroin and crack who had managed to avoid his parents' knowing of the extent of his drug use. He described his decision to cease his drug use without treatment (to 'cluck it out on my own') as due to his fear of being seen entering a treatment service. Another long-time heroin user described himself and his drug use in the following way:

you see I am not a drug user, you know, I don't smoke crack cocaine, I don't take Valium and all that, all right I take heroin but, you know, I don't do it in front of anyone, it is something that is very private. I am not a social user, you know, I used to get up every morning for the kids, you know what I mean, get them washed, dressed, ready for school, bed, take them to school, pick them up, you know (Alan).

Clearly Alan - an ex-soldier who even as a heroin user claims to live a life of disciplined routine - had not been able to manage his drug use so as to avoid becoming the subject of a public gaze. He had received a custodial sentence for a crime he had carried out in order to fund his drug use. This account is remarkable in that he attempts, none-the-less, to manage his discredited identity in such a way that refuses the label of a disreputable drug user/ junkie. Indeed, Alan's description of the way in which he takes heroin and leads his life contains reverse instructions for the popular definition of a junkie: he is discrete about his drug use (he infers that junkies have no qualms about who they use drugs in front of), he does not take drugs in groups (junkies take drugs with their associates, other junkies); he only takes heroin in order, he says elsewhere in the interview, to stay 'normal' (junkies take a number of drugs in order to get 'out of their heads' - again there is the implication that his drug use is medical in nature), he leads an ordered life in which he gets up in the morning (junkies lead a nocturnal, chaotic life not 'attuned to the clock' (Room, 2003)), he was able to take care of his children (junkies neglect their children), he was able to get his children to school in the morning and be there to collect them from school (the children of junkies are late for or do not attend school). Although as a result of his criminal conviction and use of heroin, Alan would fit with the Sun newspaper's category of a 'criminal junkie', he is able to remove himself from this identity and distinguish himself from the junkie world. In the language of some drug treatment services it might be considered that Alan has failed to face-up to the underlying nature of his addiction, and is 'in denial' about his addict identity. In this account of taking heroin to stay normal (rather than for the purposes of any transgressive pleasure), Alan is able to vividly describe and counterpoise himself to - the discursive object of the junkie. He is refusing the shaming junkie identity in favour of a definition of himself as medical user of heroin, thus part of a dominant moral community that judges him as wanting in so many ways. As Young (1971) also noted, various identities are available to the drug user. They are chosen on the basis of the advantages that they offer. For Alan, the junkie identity has no advantages and so is rejected.

\section{Stigma and the treatment regime}

For several heroin users the treatment regime itself became stigmatising. They referred to segregation in pharmacies and the supervised consumption of medication as a humiliation:

and the way they treat you in the chemist...'you go over there in the corner and only come between one and two o'clock' or something like that 'and you come at certain hours so you don't frighten my customers' (Alisdair).

For Alisdair, whose diamorphine prescription had been re-categorised from 'drug abuse' to 'pain management' because of complex health problems brought about by his long term misuse of alcohol, the humiliating treatment meted out to those picking-up methadone was more noticeable now that he was no longer, in the eyes of the pharmacist, a junkie and no longer subject to the strictures of collecting his prescription at particular times of day, standing in particular places at the pharmacy counter, or taking the medication in front of the pharmacist - 'I'm treated different and it just shows you the way that they do treat people'. Alisdair is describing here how the moral significance of drug use as a medical problem versus addiction is made manifest, and how, practically, stigma is interpersonally enacted.

The numerous ways that methadone maintenance prescriptions marked respondents out as separate from and outside normal life were emphasised in the barrier that daily pick-ups of prescriptions presented for working, for travel both within and outside the UK.

it seems like you're trapped when you get on your script because like work-wise you've got to worry about 
making the chemist everyday. Making your appointments to get tested and everything (Keith).

Keith was one of many of the drug users we interviewed who described how substitute prescribing programmes disrupted their aspirations for economic activity and a 'conventional stake in life' (Waldorf, Reinarman, \& Murphy, 1991). Many of the drug users we interviewed were socially conservative, both in their depiction of dirty, criminal junkies and their adherence to dominant values of work, decency and family life. They displayed the frustrations associated with Young's (1999: 81) concept of 'cultural bulimia', or the simultaneous inclusion and exclusion of people who are disadvantaged by the operation of the neo-liberal market. They often accepted dominant cultural values while being denied the resources to achieve them. In actively refusing the humiliation of the junkie identity and espousing their own cultural normality, such respondents were effectively hanging on, however precariously, to the possibility of social incorporation. Respondents expressed frustrations about how substitute prescribing made leading a 'normal' life - including working - difficult, and while methadone regimes presented logistical problems, use of heroin was described by several respondents as being compatible - as in Alan's case above - with normality. The process of assessment for a substitute prescription programme conflicted with work for this respondent:

you had to go through all this palaver to get on to the programme at that time and I just didn't have the time; I was working lots of hours. It was easier really to go up to London three times a week [to buy heroin] (Desmond).

Our interviews indicated the extent to which a substitute prescription programme may present an alternative vocation that removes its subjects into the time and space of treatment. It creates a scenario where lives are organised around the pharmacy dispensing hours and weekly appointments for testing and counselling, restricting the possibility for alternative activities, whether work, study or training and yet failing to fill time adequately either. So they risk reproducing the boredom that respondents in our study often reported had been implicated in the development of their problematic drug use.

The significance of social capital - including employment, stable accommodation, good family and social relationships, non-heroin using interests and friends who are not heroin users - in enabling users to mature out of drug use is emphasised in a follow up to Warburton et al.'s 2005 study: 21 of the 32 interviewees from the original cohort of controlled users interviewed two years later reported having either reduced or stopped taking heroin. The demands of professional life featured prominently in informants' explanations for reduction and cessation of heroin use, as did the formation of new non-drug using relationships and the distancing from those who were closely linked to heroin use. In contrast, the small number who had increased their use of heroin reported doing so in response to problems in their personal and professional life (McSweeney \& Turnbull, 2007: 15-16). It has been argued that all recovery is 'natural recovery' (Edwards, 2000) and social capital plays a vital role in enabling users to sustain their decisions to manage or end their use:

'Peoples' ability to become immersed in conventional life and develop meaningful relations is influenced by the pre-existing social capital they bring with them into their addiction as well as the amount of social capital they are able to retain through their dependencies' (Granfield \& Cloud, 2001: 1554).

The decision open to both Warburton et al.'s and Granfield and Cloud's research subjects - either to use heroin in a controlled way or to cease their substance mis/use without recourse to treatment - are linked to choices more generally available in lives in which illicit substance use does not provide the sole link to social and financial networks and in which sources of family support can be taken for granted. If social capital would seem to provide a kind of preventative insulation from the degradation and stigma of the junkie identity - and it is perhaps a paradox of late modernity that the individuated consumer it exalts is greater enabled to become responsible for her over-consumption by virtue of the network of social relations and capital in which she is embedded - it is an open question whether the junkie status is more stigmatising for those with more to lose both materially and in terms of status. Our interview data indicates that many drug users who have little social capital are also keen to avoid identification as a junkie.

\section{Communities of users}

We have described rejection of the junkie identity by some of those interviewed for this study and how drug users are able to deploy pejorative discourse in order to simultaneously 'other' the junkie identity and to manage their own discreditable identities. In contrast to Granfield and Cloud's respondents whose 'natural recovery' was enabled by relationships with individuals who were not drug users, for many of those we interviewed the community of drug users of which they formed a part was their main source of social bonds. For a number of those interviewed 'getting clean' in prison was followed by immediate re-immersion, on release, into drug using networks and drug use. James, who at 28 stated that he had spent most of his life in prison for drug-related offences, described the following scenario:

I was gym orderly so I was always keeping fit but the minute I'm outside, straight back on it. Straight that day I'm back on it because I bump into people that I know and they're on it and I think yeah, fuck it, I'll go and have a little boot [injection of heroin] and that's it, but it doesn't work like that (James).

In the closed environment of prison (where drugs are available to those who want and can afford them - several respondents describing acquiring a heroin habit in prison), James presents himself as capable of work, of responsibility and of keeping fit. The hygienic state of being drug free clean - is a powerful metaphor and of course contains its antithesis of the dirty junkie (Weinberg, 2000). 
The inevitability of habitual heroin use after one 'little boot' in the world outside prison was a common narrative in interviews with disengaged drug users who described being drawn back into a life dedicated to drug-taking on return to their families and to their community. They describe both the impossibility of 'passing' as non-drug users, as well as the transgressive pleasure of drug use itself:

Because when you get clean and you go back down there and it's all your old using buddies and that and they're still using, they're telling you how great it is, it's just you know, for someone like me I can only stay strong for a little while before I start dabbling again (Keith).

Clearly our sample was based on those who had disengaged from drug treatment services and we are not arguing that some drug users do not 'stay strong' and go out of their way to reinvent themselves as former users who no longer 'dabble'. If we refer back to Alan's interview extract in which he was so keen to distinguish himself from a problematic drug user, drug use is often not a private but a highly sociable experience peopled, as in Keith's extract, with 'using buddies'. Ambivalence was thus expressed in relation to the community as a source both of alternative social capital, and at the same time the 'lion's den' that they were inevitably thrown back into after release from prison, a stay in residential rehabilitation or time abroad. Others who had intentionally moved somewhere new where they were not known and identifiable as users described an equally inevitable process of acculturation into the local drug scene:

I came down here to get away from the drugs and it was good at the start, but then you can spot a drug user anywhere and as soon as you know one person you end up taking it. You end up 'I'll just try a little bit' and you end up addicted to it again (Alisdair).

Here Alisdair describes not bumping into an old acquaintance but seeking out a new one as a gateway into a drug using network. His account parallels Childress' et al.'s observation, cited by Weinberg, of the tendency for former users to crave drugs when they are faced with situations reminiscent of their old drug using settings and associates (Childress, Ehrman, Rohsenow, Robbins, \& O'Brien, 1992; Weinberg, 1997). While there is of course an element of choice in once more adopting the drug using life style, its temptations are evident given the low wage, insecure work that it might enhance or possibly replace (Carnwath \& Smith, 2002). Choices are after all constrained by the alternatives available. As Weinberg (1997) has argued, drug use represents a coping technique in relation to a specific setting and is not necessarily generaliseable to the whole of an individual's life. While Alisdair has it within his power to relocate from one part of the British Isles to another and to imagine a more prosperous and successful life, his experience of structural disadvantage means that he is likely to find himself again and again in the sort of settings and amongst the kind of associates that are conducive to habitual drug use.

In addition to interviewing drug users, we also interviewed 16 drug treatment workers for this project. Treatment staff described the status and excitement involved in drug-taking for a population of socially excluded young men in particular, for whom status and excitement are otherwise starkly lacking. Being part of the community that drug-taking provides can be attractive as it delivers a source of identity which provides an endless round of business to take care of (Preble \& Casey, 1969) and gives meaning to this persistent pursuit of 'action' (Katz, 1988). It is members of this drug using/offending community who, as discussed earlier, are associated with drug treatment services and carry the stigma that deters some drug users from attending such services. Indeed, for several of those interviewed, the communal experience of the treatment programme paralleled their existing social networks.

A lot of my friends are on [treatment orders] and a lot of my friends were at [Treatment Service] and...they finish at four o'clock and they gang up and they go shoplifting together and they use together. A lot of them know each other from the area as well so it's all that just being friends back in the drug house really (John).

Respondents described meeting old friends and acquaintances - from prison and the streets - in day programme settings. These settings and relationships may hinder the construction of the 'non-addict identity' that is important in recovery from dependent drug use (McIntosh \& McKeganey, 2000).

\section{Conclusion}

Discursively, the policy focus on "high-harm causing users" continues to support the labelling of a certain group of drug users as social dirt; a source of both contamination and danger to other members of society. The use of HHCUs in policy documents is reflected in the use of the term 'junkie' by popular newspapers and by drug users themselves (as demonstrated in this article), as well as by other residents of areas that are affected by socio-economic deprivation and crime (as shown in the interviews carried out by Neild, 2007). The term continues to denote a binary opposition between people who embody purity and productivity, and others who embody pollution and deviant consumption - an opposition that elaborates a narrative by which to understand the risks and dangers of contemporary life. In Bauman's (2007) terms, offending heroin users are seen as "flawed consumers" who can serve only one useful purpose; to allow "diffuse terrors to focus on a target which is reassuring just for being specific and tangible" (Bauman, 2007: 125). Their failure to consume appropriately is seen as resulting from individual weakness, and not from social problems. The task of catching them as they fall from society is being taken from the safety net of the post-War welfare state by the prison - although prison can be avoided by those who agree to conform to the norms and constraints of drug treatment.

Two main points come out of this analysis that are relevant to the delivery of treatment services. The first is that our interview data indicate that drug treatment services effectively collect their diverse service users under a category which is particularly problematic for those drug users who are younger, female, or who are not heroin users. For many of the drug users we interviewed, it seems that drug 
treatment is only for a certain category of drug user; a category which they associate with the stigmatised identity of the junkie. For these people, who are managing information about their discreditable drug use in order not to become discredited, entry to treatment would be dangerous to their own self-identity and for their relationship with the outside world. The focus of drug treatment on 'highharm causing users' of heroin and crack makes these decisions not to enter treatment more likely, both by reinforcing the idea of treatment clients as predatory criminals and by concentrating in treatment people (i.e. prolific offenders) who fit this category more closely than do the generality of people who have problems with their use of drugs.

The second of our points on treatment is that day programmes - in which large numbers of prolific offenders have been placed by Drug Treatment and Testing Orders, Drug Rehabilitation Requirements and the Drug Interventions Programme - are seen by some drug users as replicating the social setting which reinforces a commitment to drug use as the pole around which life revolves. The social world of the day programme, inhabited as it is by acquaintances from the local drug market, can exclude people who have reason to fear or distrust these acquaintances. And for those who do enter the programmes, it may provide a barrier to the creation of contacts that are outside the world of drug use. As social capital is important for recovery from drug dependence, it is essential that drug users are enabled to build the sort of social capital that supports recovery (e.g. contacts that link them to the world of work and legal leisure activities) rather than being enclosed within a world where their only contacts are with drug workers, users and dealers.

There is, then, a danger that drug treatment is seen as being only for junkies and that some forms of treatment may not help clients to escape this identity. The provision of drug treatment is one of the few areas of drug policy that is supported by the available evidence (Reuter \& Stevens, 2007). Indeed, significant resources have been spent in the UK on increasing treatment availability. But these resources have been targeted on specific kinds of drug users and have mostly been provided in specialised treatment settings. It has been argued elsewhere (McGrail, 2007; Stevens et al., 2007) that the benefits of drug treatment will be extended to a wider population of drug users if more treatment services can be provided in mainstream healthcare settings, such as GP surgeries. The analysis presented here has demonstrated how the medicalising of drug treatment can have a de-stigmatising effect for service users. We thus endorse the argument that more treatment services can be provided in generic healthcare settings. At the same time, specialist treatment services can be developed to reach a wider population of users. We are therefore arguing that drug treatment services should not only be for offending heroin and crack users, but that services can also be targeted at younger, non-opiate users and to the harder to reach populations of drug using parents and sex workers for whom the 'high harm' of drug use may be to their families, children and themselves, rather than to the profits of local retailers. Our analysis of the accounts of drug users who have decided not to engage with drug treatment services supports the suggestion that more needs to be done, both to avoid the association of treatment services with the stigmatised category of the junkie and to help those in treatment to escape the social world that is, in part, structured by this identity.

\section{References}

Atkinson, R., \& Flint, J. (2001). Accessing hidden and hard-to-reach populations: Snowball research strategies. Social Research Update Issue 33. Guildford: University of Surrey.

Bauman, Z. (2007). Consuming life. Cambridge: Polity Press.

Boeri, M. W. (2004). "Hell, I'm an addict but I ain't no junkie". An ethnographic analysis of aging heroin users. Human Organization, 63, 236-245.

Carnwath, T., \& Smith, I. (2002). Heroin century. London: Routledge.

Childress, A. R., Ehrman, R., Rohsenow, D., Robbins, S. J., \& O'Brien, C. P. (1992). Classically conditioned factors in drug dependence. In J. H. Lowinson, P. Ruiz, R. B. Millman, \& J. G. Langrad (Eds.), Substance abuse: A comprehensive text (pp. 56-69). Baltimore: Williams and Wilkins.

Copeland, J. (1997). A qualitative study of barriers to formal treatment among women who self-managed change in addictive behaviours. Journal of Substance Abuse Treatment, 14(2), 183-190.

Courtwright, D. T. (2001). Dark paradise. A history of opiate addiction in America. Cambridge, MA: Harvard University Press.

Douglas, M. (1966). Purity and danger. An analysis of concepts of pollution and taboo. London: Routledge/Kegan Paul.

Douglas, M., \& Wildavsky, A. (1982). Risk and culture: As essay on the selection of technological and environmental dangers. Berkeley: University of California Press.

Duke, K. (2006). Out of crime and into treatment? The criminalization of contemporary drug policy since tackling drugs together. Drugs: Education, Prevention and Policy, 13(5), 409-415.

Edwards, G. (2000). Editorial note: natural recovery in the only recovery. Addiction, 57(5), 747.

Goffman, E. (1968). Stigma: Notes on the management of spoiled identity. Harmondsworth: Penguin.

Granfield, R., \& Cloud, W. (2001). Social context and "natural recovery": the role of social capital in the resolution of drug-associated problems. Substance Use and Misuse, 36(11), 1543-1570.

Hacking, I. (2003). Risk and dirt. In R. Ericson, \& A. Doyle (Eds.), Risk and morality. Toronto: University of Toronto Press.

Hunt, N., \& Stevens, A. (2004). Whose harm? Harm and the shift from health to coercion in UK drug policy. Social Policy $\mathcal{E}$ 'Society, 3(4), $333-342$

Jamieson, A., Glanz, A., \& MacGregor, S. (1984). Dealing with drug misuse: Crisis intervention in the city. London: Tavistock.

Katz, J. (1988). Seductions of crime. Moral and sensual attractions in doing evil. New York: Basic Books.

Katz, J. (1999). How emotions work. Chicago: University of Chicago Press.

Layder, D. (1998). Sociological practice: Linking theory and social research. London: Sage.

Lee, W. (1953). Junkie: Confessions of an unredeemed drug addict. An Ace original. New York: Ace Books.

McGrail, S. (2007). Frozen out: how not to treat drug users. Druglink, 22(1), 20-22.

McIntosh, J., \& McKeganey, N. (2000). Addicts' narratives of recovery from drug use: constructing a non-addict identity. Social Science $\mathcal{E}$ Medicine, 50, 1501-1510.

McSweeney, T., \& Turnbull, P. J. (2007). Exploring user perceptions of occasional and controlled heroin use. A follow-up study. York: Joseph Rowntree Foundation. p. 36.

Malins, P., Fitzgerald, J., \& Threadgold, T. (2006). Spatial 'folds': the entwining of bodies, risks and city spaces for women injecting drug users in Melbourne's Central Business District. Gender, Place and Culture, 13(5), 509-527.

Neild, J. (2007). Presentation: 'Get rid of the junkies that will make it better round here!'. Conference of the British Society of Criminology, London.

Parker, H. (7 May, 2007). Drug strategy loses its way. Drink \& Drug News 6-7.

Pearson, G. (1987). The new heroin users. Oxford: Basil Blackwell.

PMSU. (2003a). SU drugs report. Phase 1 report: Understanding the issues. London: Prime Minister's Strategy Unit.

PMSU. (2003b). SU drugs report. Phase 2 report: Diagnosis and recommendations. London: Prime Minister's Strategy Unit.

PMSU. (2007). Building on progress: Security, crime and justice. London: Prime Minister's Strategy Unit, Cabinet Office. 
Preble, E., \& Casey, J. (1969). Taking care of business - the heroin user's life of the street. The International Journal of the Addictions, 4(1), 1-24.

Reinarman, C. (2005). Addiction as accomplishment: the discursive construction of disease. Addiction Research E Theory, 13(4), 307-320.

Reuter, P., \& Stevens, A. (2007). An analysis of UK drug policy. London: UK Drug Policy Commission.

Rhodes, T., Watts, L., Davies, S., Martin, A., Smith, J., Clark, D., et al. (2007). Risk, shame and the public injector: a qualitative study of drug injecting in South Wales. Social Science \& Medicine, 65(3), 572-585.

Ritter, A. J., Fry, C. L., \& Swan, A. (2003). The ethics of reimbursing injecting drug users for public health research interviews: what price are we prepared to pay? International Journal of Drug Policy, 14(1), 1-3.

Rødner, S. (2005). "I am not a drug abuser, I am a drug user": a discourse analysis of 44 drug users' construction of identity. Addiction Research E' Theory, 13(4), 333-346.

Room, R. (2003). The cultural framing of addiction. Janus Head, 6(2), 221-234.

Seddon, T. (2005). Paying drug users to take part in research: justice, human rights and business perspectives on the use of incentive payments. Addiction Research \& Theory, 13(2), 101-109.

Shewan, D., \& Dalgarno, P. (2006). Evidence for controlled heroin use? Low levels of negative health and social outcomes among nontreatment heroin users in Glasgow (Scotland). British Journal of Health Psychology, 10, 33-48.

Stevens, A. (2007). When two dark figures collide: evidence and discourse on drug-related crime. Critical Social Policy, 27(1), 77-99.
Stevens, A., Radcliffe, P., Sanders, M., Hunt, N., Turnbull, P., \& McSweeney, T. (2007). Early exit: Estimating and explaining early exit from drug treatment. London: Department of Health.

Valverde, M. (1998). Diseases of the will. Alcohol and the dilemmas of freedom. Cambridge: Cambridge University Press.

Waldorf, D. (1973). Becoming a heroin addict. In D. Waldorf (Ed.), Careers in dope (pp. 29-46). Englewood Cliffs, NJ: Prentice Hall.

Waldorf, D., Reinarman, C., \& Murphy, S. (1991). Cocaine changes. The experience of using and quitting. Philadelphia: Temple University Press.

Warburton, H., Turnbull, P. J. \& Hough, M. (2005). Occasional and controlled heroin use: Not a problem? York: Joseph Rowntree Foundation.

Weinberg, D. (1997). Lindesmith on addiction: a critical history of a classic theory. Sociological Theory, 15(2), 150-161.

Weinberg, D. (2000). "Out there": the ecology of addiction in drug abuse treatment discourse. Social Problems, 47(4), 606-621.

Yang, L. H., Kleinman, A., Link, B. G., Phelan, J. C., Lee, S., \& Good, B. (2007) Culture and stigma: adding moral experience to stigma theory. Social Science \& Medicine, 64(7), 1524-1535.

Young, J. (1971). The drugtakers: The social meaning of drug use. London: Paladin.

Young, J. (1999). The exclusive society. London: Sage.

Young, J. (2004). Voodoo criminology and the numbers game. In J. Ferrell, K. Hayward, W. Morrison, \& M. Presdee (Eds.), Cultural criminology unleashed (pp. 13-27). London: Glasshouse Press.

Zinberg, N. E. (1984). Drug, set, and setting: The basis for controlled intoxicant use. New Haven: Yale University. 
Preble, E., \& Casey, J. (1969). Taking care of business - the heroin user's life of the street. The International Journal of the Addictions, 4(1), 1-24.

Reinarman, C. (2005). Addiction as accomplishment: the discursive construction of disease. Addiction Research E Theory, 13(4), 307-320.

Reuter, P., \& Stevens, A. (2007). An analysis of UK drug policy. London: UK Drug Policy Commission.

Rhodes, T., Watts, L., Davies, S., Martin, A., Smith, J., Clark, D., et al. (2007). Risk, shame and the public injector: a qualitative study of drug injecting in South Wales. Social Science \& Medicine, 65(3), 572-585.

Ritter, A. J., Fry, C. L., \& Swan, A. (2003). The ethics of reimbursing injecting drug users for public health research interviews: what price are we prepared to pay? International Journal of Drug Policy, 14(1), 1-3.

Rødner, S. (2005). "I am not a drug abuser, I am a drug user": a discourse analysis of 44 drug users' construction of identity. Addiction Research E' Theory, 13(4), 333-346.

Room, R. (2003). The cultural framing of addiction. Janus Head, 6(2), 221-234.

Seddon, T. (2005). Paying drug users to take part in research: justice, human rights and business perspectives on the use of incentive payments. Addiction Research \& Theory, 13(2), 101-109.

Shewan, D., \& Dalgarno, P. (2006). Evidence for controlled heroin use? Low levels of negative health and social outcomes among nontreatment heroin users in Glasgow (Scotland). British Journal of Health Psychology, 10, 33-48.

Stevens, A. (2007). When two dark figures collide: evidence and discourse on drug-related crime. Critical Social Policy, 27(1), 77-99.
Stevens, A., Radcliffe, P., Sanders, M., Hunt, N., Turnbull, P., \& McSweeney, T. (2007). Early exit: Estimating and explaining early exit from drug treatment. London: Department of Health.

Valverde, M. (1998). Diseases of the will. Alcohol and the dilemmas of freedom. Cambridge: Cambridge University Press.

Waldorf, D. (1973). Becoming a heroin addict. In D. Waldorf (Ed.), Careers in dope (pp. 29-46). Englewood Cliffs, NJ: Prentice Hall.

Waldorf, D., Reinarman, C., \& Murphy, S. (1991). Cocaine changes. The experience of using and quitting. Philadelphia: Temple University Press.

Warburton, H., Turnbull, P. J. \& Hough, M. (2005). Occasional and controlled heroin use: Not a problem? York: Joseph Rowntree Foundation.

Weinberg, D. (1997). Lindesmith on addiction: a critical history of a classic theory. Sociological Theory, 15(2), 150-161.

Weinberg, D. (2000). "Out there": the ecology of addiction in drug abuse treatment discourse. Social Problems, 47(4), 606-621.

Yang, L. H., Kleinman, A., Link, B. G., Phelan, J. C., Lee, S., \& Good, B. (2007) Culture and stigma: adding moral experience to stigma theory. Social Science \& Medicine, 64(7), 1524-1535.

Young, J. (1971). The drugtakers: The social meaning of drug use. London: Paladin.

Young, J. (1999). The exclusive society. London: Sage.

Young, J. (2004). Voodoo criminology and the numbers game. In J. Ferrell, K. Hayward, W. Morrison, \& M. Presdee (Eds.), Cultural criminology unleashed (pp. 13-27). London: Glasshouse Press.

Zinberg, N. E. (1984). Drug, set, and setting: The basis for controlled intoxicant use. New Haven: Yale University. 